\title{
Conservative Management of Extensive latrogenic Aortic Dissection
}

\author{
Derrick Y. Tam, MD ${ }^{1}$, Amine Mazine, MD, MSc ${ }^{1}$, Asim N. Cheema, MD, PhD², \\ Bobby Yanagawa, $\mathrm{MD}, \mathrm{PhD}^{1^{*}}$ \\ ${ }^{1}$ Divisions of Cardiac Surgery, St. Michael's Hospital, University of Toronto, Toronto, Ontario, Canada \\ ${ }^{2}$ Divisions of Cardiology, St. Michael's Hospital, University of Toronto, Toronto, Ontario, Canada
}

\begin{abstract}
latrogenic aortic dissection (IAD) is a rare complication of percutaneous coronary interventions $(\mathrm{PCI})$. There are no clear guidelines for IAD management, and limited data are available. Registry data and case series combined with extrapolations from our experience with spontaneous Type-A dissections suggest that very limited dissections are often managed conservatively with coronary stenting of the entry tear when possible, while more extensive dissections are managed surgically. We present a case report of a 50-year-old woman who underwent $\mathrm{PCl}$ for an ST-elevation myocardial infarction that resulted in an extensive IAD from the ostium of the right coronary artery to the aortic root, ascending aorta, and aortic arch. While the current evidence strongly supports surgical management of such extensive dissection, our patient was successfully managed conservatively with complete resolution according to short-term computed tomography imaging. This case suggests that conservative management may be a reasonable approach for select patients with extensive IAD. Copyright @ 2016 Science International Corp.
\end{abstract}

\section{Key Words:}

latrogenic aortic dissection - Percutaneous coronary intervention

\section{Introduction}

latrogenic aortic dissection (IAD) is a rare compli-

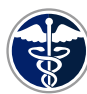

Fax +1 2037853552

E-Mail: aorta@scienceinternational.org

http://aorta.scienceinternational.org

\author{
() 2016 AORTA \\ Published by Science International Corp. \\ ISSN 2325-4637 \\ Accessible online at: \\ http://aorta.scienceinternational.org
}

cation of percutaneous coronary intervention $(\mathrm{PCl})$ [1-4]. In contrast to spontaneous Type-A aortic dissection (AD), where emergent surgical intervention is recommended to avoid devastating sequelae, the optimal management for IAD is less clear. While initial studies reported a $50 \%$ early mortality following surgical management of IAD, recent registry data suggest that mortality is comparable to that of spontaneous ADs ( $16 \%$ for IAD vs. $17 \%$ for spontaneous AD) $[3,4]$. Patients with IAD are typically older compared to patients with spontaneous AD but are usually diagnosed immediately and thus require less extensive surgery. Herein, we present a case of successful conservative management of IAD following $P C l$ extending from the right coronary artery (RCA) into the aortic root and arch.

\section{Case Presentation}

A 50-year-old otherwise healthy female smoker presented at the emergency department with a 2-day history of gastric reflux-like symptoms. An electrocardiogram revealed ST segment elevation in the inferior leads. The patient was therefore transferred immediately for a coronary angiogram. A right radial approach was utilized and showed normal left main and left anterior descending arteries and a circumflex with a $70 \%$ obtuse marginal

* Corresponding Author:

Bobby Yanagawa, MD, PhD, FRCSC

Division of Cardiac Surgery, Department of Surgery,

University of Toronto, St. Michael's Hospital

Toronto, Ontario, Canada

Tel: +1-416-864-5706; Fax: +1-416-864-5031; E-Mail: yanagawab@smh.ca 
lesion. The RCA had a 99\% occlusive thrombus with distal TIMI (Thrombolysis in Myocardial Infarction) 2 flow. A wire was passed to yield a proximal RCA dissection that involved the entire length of the vessel. Three drug-eluting stents were deployed, resulting in TIMI 3 flow; however, the dissection had extended retrogradely into the aortic root and arch (Figure $1 A, B, C)$. Furthermore, the dissection flap itself was not covered, demonstrating persistent communication with the false lumen. Emergent computed tomography (CT) confirmed the diagnosis of IAD, and the patient was then transferred to our hospital for further management. She remained pain-free and hemodynamically stable throughout the assessment and transfer.

On arrival, repeat CT scan demonstrated a stable dissection with no active extravasation into the false
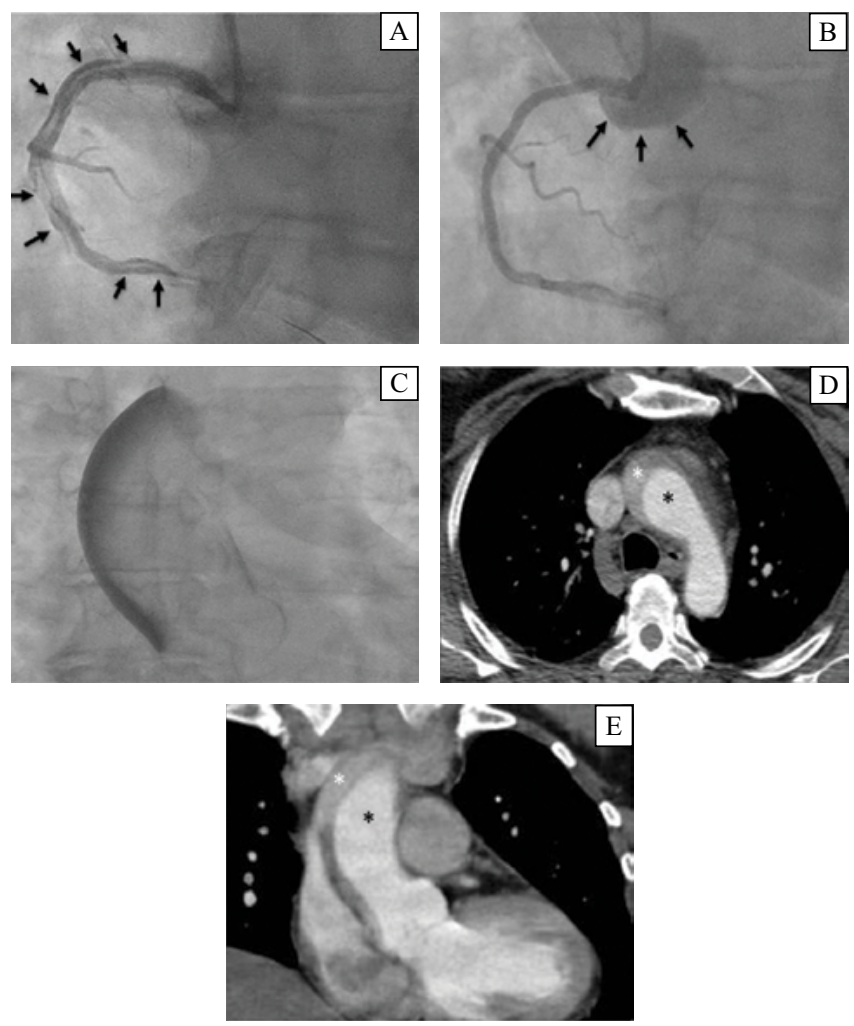

Figure 1. Coronary angiogram. Right coronary artery iatrogenic dissection (Panel $A$, arrows) with contrast into the false lumen in the aortic root (Panel $B$, arrows) and ascending aorta (Panel $C$ ). Chest computed tomography confirmed a dissection in the ascending aorta (Panel D, false lumen, white*; true lumen, black*) and aortic arch (Panel $E$, false lumen, white*; true lumen, black*). lumen, no pericardial effusion, and no aortic insufficiency (Figure 1D, E). The patient received a labetalol infusion to target a systolic blood pressure $<120 \mathrm{~mm}$ $\mathrm{Hg}$, and aspirin and ticagrelor therapy was continued. Another CT scan the following morning demonstrated a decrease in the size of the false lumen from 11 $\mathrm{mm}$ to $7 \mathrm{~mm}$ at the sinus of Valsalva and no evidence of contrast enhancement in the false lumen. A dissection flap was noted to extend across the RCA ostium, but the flap did not limit blood flow. The patient was discharged on day 3 with orders for ramipril, bisoprolol, and clonidine, as well as dual antiplatelet therapy. At the 2-and 4-month clinical follow-up visits, the patient remained asymptomatic. The 4-month CT scan showed complete resolution of the dissection with a patent RCA (Figure 2).

\section{Discussion}

IAD is a rare complication of $\mathrm{PCl}$ with an estimated incidence of $0.02 \%$ to $0.06 \%$ [1]. Patients with IAD are often older than those with spontaneous AD [13]. The RCA is commonly the site of IAD. Dunning et al. classified IAD based on extent of dissection: Class I dissections involve the ipsilateral aortic cusp, Class Il dissections involve the ipsilateral cusp with extension of $<40 \mathrm{~mm}$ up the aorta, and Class III dissections involve the ipsilateral cusp with extension of $>40 \mathrm{~mm}$ up the aorta. These authors advocated for coronary stent therapy for Class I and II IAD, and surgery for Class III IAD [2]; however, these recommendations were based on a limited series of patients,
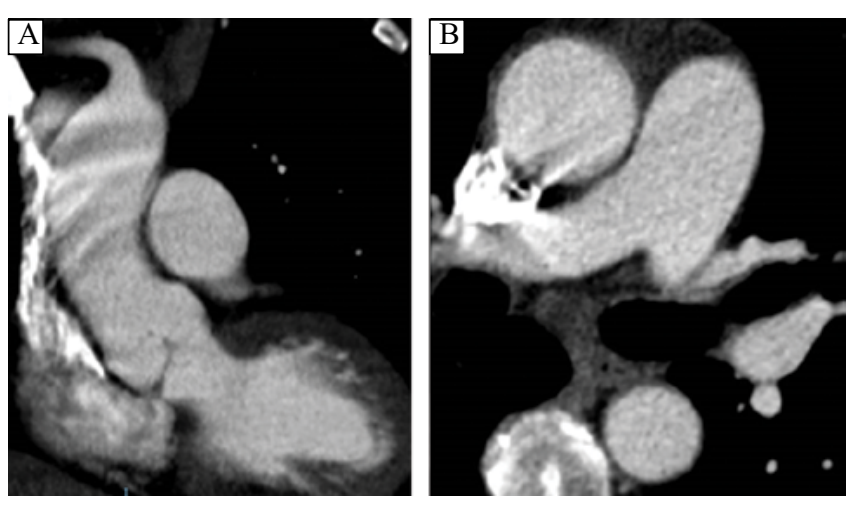

Figure 2. Chest computed tomography revealed complete resolution of the dissection in the sagittal (Panel A) and axial (Panel B) views 4 months after the initial acute dissection event. 
and the outcome of conservative management for Class III IAD was not evaluated. More recently, data from the Registry on Aortic latrogenic Dissection (RAID) was found to support conservative management of IAD, although the majority (77\%) of cases had limited dissections (Dunning I and II), and more than half (35 of 74 patients) used stents to cover the intimal tear [1].

Our patient had an extensive dissection (Dunning class III) that extended into the aortic arch with a coronary dissection tear that was not covered. While there are no clear guidelines for IAD management, Dunning et al. advocated for surgical management for such class III dissections [2]. Nonetheless, we elected to pursue conservative management due to the absence of evidence of active contrast extravasation into the false lumen on a CT scan hours after the dissection occurred, as well as some resolution on the predischarge CT. Importantly, considerable dissec- tion into the aortic root, aortic insufficiency, and hemopericardium are general indications for urgent surgical intervention; however, none of these conditions were observed in our patient. Furthermore, persistent active extravasation of blood into the false lumen on serial imaging would also prompt urgent surgery, but this condition was not observed in our patient. This case suggests that conservative management with serial imaging, aggressive blood pressure control, and close follow-up may be a reasonable approach for select IAD cases.

\section{Conflict of Interest}

The authors have no conflict of interest relevant to this publication.

\section{Comment on this Article or Ask a Question}

\section{References}

1. Núñez-Gil IJ, Bautista $D$, Cerrato $E$, Salinas $P$, Varbella $F$, Omedè $P$, et al. Incidence, management, and immediate- and longterm outcomes after iatrogenic aortic dissection during dagnostic or interventional coronary procedures. Circulation. 2015;131:2114-2119. DOI: 10.1161/CIRCULATIONAHA.115.015334

2. Dunning DW, Kahn JK, Hawkins ET, O'Neill WW. latrogenic coronary artery dissections extending into and involving the aortic root. Catheter Cardiovasc Interv. 2000;51:387-393. DOI: 10.1002/1522726 X(200012) $51: 4<387::$ A ID CCD3>3.0.CO;2-B
3. Rylski B, Hoffmann I, Beyersdorf F, Suedkamp M, Siepe M, Nitsch B, et al. latrogenic acute aortic dissection type $A$ : insight from the German Registry for Acute Aortic Dissection Type A (GERAADA). Eur J Cardiothorac Surg. 2013;44:353-359. DOI: 10.1093/ejcts/ezt055

4. Leontyev S, Borger MA, Legare JF, Merk D, Hahn J, Seeburger J, et al. latrogenic type A aortic dissection during cardiac procedures: early and late outcome in 48 patients. Eur J Cardiothorac Surg. 2012;41:641-646. DOI: 10.1093/ejcts/ezr070
Cite this article as: Tam DY, Mazine A, Cheema AN, Yanagawa B. Conservative Management of Extensive latrogenic Aortic Dissection. AORTA (Stamford). 2016;4(6):229-231. DOI: http://dx.doi. org/10.12945/j.aorta.2016.16.040 